\title{
Ovarian cancer risk and common variation in the sex hormone-binding globulin gene: a population-based case-control study
}

\author{
Montserrat Garcia-Closas*1, Louise A Brinton'1, Jolanta Lissowska ${ }^{3}$, \\ Douglas Richesson ${ }^{1}$, Mark E Sherman ${ }^{1}$, Neonila Szeszenia-Dabrowska ${ }^{4}$, \\ Beata Peplonska ${ }^{4}$, Robert Welch ${ }^{2}$, Meredith Yeager ${ }^{2}$, Witold Zatonski ${ }^{3}$ and \\ Stephen J Chanock ${ }^{2}$
}

\begin{abstract}
Address: ${ }^{1}$ Division of Cancer Epidemiology and Genetics, National Cancer Institute, National Institutes of Health, Department of Health and Human Services, 6120 Executive Boulevard, suite 550, Rockville, MD 20952-7234, USA, ${ }^{2}$ Core Genotyping Facility, Division of Cancer Epidemiology and Genetics, National Cancer Institute, National Institutes of Health, Department of Health and Human Services, USA, ${ }^{3}$ Department of Cancer Epidemiology and Prevention, M. Sklodowska-Curie Institute of Oncology and Cancer Center, Warsaw, Poland and ${ }^{4}$ Department of Occupational and Environmental Epidemiology, Nofer Institute of Occupational Medicine, Lodz, Poland

Email: Montserrat Garcia-Closas* - montse@nih.gov; Louise A Brinton - brintonl@exchange.nih.gov; Jolanta Lissowska - lissowsj@coi.waw.pl; Douglas Richesson - richessond@mail.nih.gov; Mark E Sherman - shermanm@exchange.nih.gov; Neonila SzeszeniaDabrowska -wies@porta.imp.lodz.pl; Beata Peplonska - beatap@imp.lodz.pl; Robert Welch - welchr@mail.nih.gov; Meredith Yeager - yeagerm@mail.nih.gov; Witold Zatonski - zatonskiw@coi.waw.pl; Stephen J Chanock - chanocks@exchange.nih.gov

* Corresponding author
\end{abstract}

\section{Published: 5 April 2007}

BMC Cancer 2007, 7:60 doi:10.1186/147|-2407-7-60
Received: II November 2006

Accepted: 5 April 2007

This article is available from: http://www.biomedcentral.com/147/-2407/7/60

(c) 2007 Garcia-Closas et al; licensee BioMed Central Ltd.

This is an Open Access article distributed under the terms of the Creative Commons Attribution License (http://creativecommons.org/licenses/by/2.0), which permits unrestricted use, distribution, and reproduction in any medium, provided the original work is properly cited.

\begin{abstract}
Background: The sex hormone-binding globulin (SHBG) is a carrier protein that modulates the bio-availability of serum sex steroid hormones, which may be involved in ovarian cancer. We evaluated whether common genetic variation in SHBG and its $3^{\prime}$ neighbor ATPIB2, in linkage disequilibrium, is associated with the risk of epithelial ovarian cancer.

Methods: The study population included 264 women with ovarian carcinoma and 625 controls participating in a population-based case-control study in Poland. Five common single nucleotide polymorphisms (SNPs) in SHGB and five in ATPIB2 were selected to capture most common variation in this region.

Results: None of the SNPs evaluated was significantly associated with ovarian cancer risk, including the putative functional SNPs SHBG D356N (rs6259) and -67G>A 5'UTR (rs l79994I). However, our data were consistent with a decreased ovarian cancer risk associated with the variant alleles for these two SNPs, which have been previously associated with increased circulating levels of SHBG.
\end{abstract}

Conclusion: These data do not support a substantial association between common genetic variation in $S H B G$ and ovarian cancer risk. 


\section{Background}

Hormonal stimulation of ovarian epithelial cells has been proposed as a mechanism for carcinogenesis of the ovaries [1]. The evidence for sex steroid hormones playing a role in ovarian cancer is primarily indirect, based on animal and in vitro studies, as well epidemiological observations [1], while the relationship between circulating levels of sex steroids and ovarian cancer risk has not been clearly demonstrated $[2,3]$.

The sex steroid hormone-binding globulin (SHBG) gene regulates the action of sex steroid hormones by modulating their bioavailability to target tissues such as the ovaries [4]. The SHBG gene is located on the short arm of chromosome 17. A non-synonymous SNP in exon 8 results in an amino acid substitution of asparagine for aspartic acid (D356N, rs6259) in the SHBG protein, and the asparagine (N) allele of SHBG has been associated with elevated circulating levels of SHBG in post-menopausal women [5-7]. An additional SNP in the $5^{\prime}$ untranslated region (UTR) of SHBG has also been associated with elevated SHBG levels [6]. These data suggest that common variation in SHBG has functional relevance and thus, could affect the risk of hormonally-related cancers.

We performed a detailed assessment of common genetic variation in $S H B G$ and evaluated the possibility of an association with ovarian cancer risk in the Polish Ovarian Cancer Study. We included SNPs in the SHBG 3' flanking gene ATPase, $\mathrm{Na}+\mathrm{K}+$ transporting beta 2 polypeptide (ATP1B2) because of the observation of linkage disequilibrium (LD) that extends across $S H B G$ and ATP1B2 based on a re-sequencing study [8]. The enzyme encoded by $A T P 1 B 2$ is involved in establishing and maintaining the electrochemical gradients of $\mathrm{Na}$ and $\mathrm{K}$ ions across the plasma membrane. Inclusion of neighboring genes in studies of relationships between disease and common genetic variation is of interest because they could affect the regulation of the protein of interest.

\section{Methods \\ Study population}

The Polish Ovarian Cancer Study is a population-based case-control study of ovarian cancer conducted among female residents of Warsaw and Lodz (Poland), 20-74 years of age. Eligible cases consisted of all women newly diagnosed with histologically confirmed ovarian carcinoma or a borderline tumor identified during the study period (June 2001 - December 2003). We identified a total of 437 eligible cases. Most (76\%) cases were idenditfied through a rapid ascertainment system in participating hospitals, and the remaining cases (24\%) missed by this system were identified through cancer registries. Control women were randomly selected within matching strata from complete population lists (PESEL database) of War- saw and Lodz residents from 2001 to 2004, and were frequency matched to cases on age (5-year groups) and study site (Warsaw and Lodz). Women who reported a previous diagnosis of ovarian cancer or bilateral oopherectomy were excluded as controls. Of the eligible cases and controls, $78 \%$ and $69 \%$, respectively, agreed to participate in the study. The main reasons for non-participation among eligible subjects included: refusal to participate $(11 \%$ cases and $24 \%$ controls); unable to locate (3\% cases and $7 \%$ controls), and deceased ( $7 \%$ cases and $<0.1 \%$ controls). This resulted in 341 cases and 1994 controls participating in the main study.

All participants underwent a personal interview regarding known or suspected ovarian cancer risk factors. The median time from diagnosis to interview was 2.4 months, ranging from 5 days to one year. Of the interviewed women, 315 (92\%) cases and 1911 (96\%) controls provided a blood or buccal cell sample for DNA extraction; however, eight of these cases were excluded because of limited amounts of DNA or quality control problems. This report is limited to carcinomas; therefore 22 cases with borderline tumors and 21 cases with non-epithelial tumors were further excluded from the analyses, leaving 264 cases ( 241 with blood and 23 with buccal cell DNA). For costs-efficiency, we randomly selected a sample of 625 controls with blood DNA to approximate a 1:2 case:control ratio. Thus, final analyses included a total of 264 cases and 625 controls. All study participants were of Polish Caucasian origin. The study protocol was reviewed and approved by local and NCI Institutional Review Boards (IRBs). All participants provided written informed consent.

\section{Genotyping}

Single nucleotide polymorphism (SNP) selection was based on a re-sequence analysis of TP53 and its neighboring genes, which include SHBG and ATP1B2, performed in 94 healthy Norwegian women and 102 individuals in the SNP500 Cancer panel [8]. SNPs in SHBG and ATP1B2 with a minor allele frequency $>0.05$ were identified during a re-sequence analysis of all exons, evolutionarily conserved regions and promoter regions and were genotyped in the Polish Ovarian Cancer Study. Genotype analyses were performed at the Core Genotyping Facility (CGF) of the Division of Cancer Epidemiology and Genetics, NCI for 5 SNPs in SHBG (rs1799941, -67G>A 5'UTR; rs6257, IVS1-17T>C; rs6259, Ex8+6G>A (D356N); rs727428, $1121 \mathrm{bp} \mathrm{3'}$ of STP T>C; and rs 164154431959 bp 3' of STP $\mathrm{T}>\mathrm{C}$ ); and 5 SNPs in ATP1B2 (rs1641536, -8852T>C; rs1641535 -8703T>C; rs1624085 x2G>C; rs1641512, Ex7+414G>A).

Description and methods for each genotype assay can be found at $[9,10]$. Duplicated DNA pairs from 70 subjects in 
the study showed $100 \%$ concordance for all assays. Completion was $\geq 98 \%$ for all assays. We observed no significant departures from Hardy-Weinberg equilibrium in the control population.

\section{Statistical Analyses}

As an estimate of relative risk, odds ratios (OR) and their 95\% confidence intervals (CI) were derived from unconditional logistic regression models that included dummy variables for the matching factors, i.e. age in 5 year categories and study site (Lodz or Warsaw). The association between genotypes and ovarian cancer risk was tested using a trend test, except for rare alleles in which heterozygous and homozygous variants were combined. We evaluated heterogeneity in the ORs observed for the genotype analysis on the basis of age, number of lifetime ovulatory cycles and family history of ovarian and/or breast cancer in first degree relatives, by introducing interaction terms in logistic regression models. Number of lifetime ovulatory cycles was used as a measure of a women's potential ovulatory life, and was calculated as previously described [11].

Pairwise linkage disequilibrium (LD) was estimated between SNPs based on D'and $\mathrm{r}^{2}$ values using Haploview [12]. Block structure was determined using genotype data from the control population, and the solid spline of LD option ( $\mathrm{D}^{\prime}$ threshold $>0.80$ ). Haplotype frequencies within each block, ORs and their 95\%CIs were estimated using HaploStats (version 1.2.1) [13,14]. A global score statistic, adjusted for the matching factors age (in 5 year categories) and study site (Lodz or Warsaw), was used to evaluate the overall difference in haplotype frequencies between cases and controls.

\section{Results}

The cases included in this analysis were diagnosed at a mean (SD) age of 56.2 (11.0) years. Tumor characteristics include: $45 \%$ had serous carcinomas, $62 \%$ had distal metastases, and $52 \%$ had tumors with poor grade of differentiation (Table 1). As expected, serous, mixed and unclassified tumors were frequently poorly differentiated (69\%, 75\% and $90 \%$, respectively), with a lower percentage of poorly differentiated tumors among endometriod $(36 \%)$ and mucinous $(19 \%)$ carcinomas. Compared to control women, cases were more frequently nulliparous or had fewer full-term births, had a larger number of lifetime ovulatory cycles, and more frequently reported a first degree family history of a first-degree relative with ovarian or breast cancer (Table 1). Cases were also less likely to have used oral contraceptives. These differences were consistent with known or suspected risk factors for ovarian cancer [15].
A map of $\mathrm{LD}$ in the control population across the 10 SNPs evaluated is shown in Additional file 1. Three of the evaluated polymorphisms (rs1641537, rs1641536 and rs1641535 in ATP1B1) showed strong correlations (pairwise $\mathrm{r}^{2}>0.98$ ) and, to avoid redundancy, only data for one of the correlated SNPs are shown in Table 2. Genotypes with the variant alleles for the putative functional SNPs in SHBG, D356N (rs6259) and -67G>A 5'UTR (rs1799941), were less common among cases than controls; however, differences were not statistically significant (Table 2). These two SNPs showed low correlation $\left(\mathrm{r}^{2}=\right.$ 0.03). Evaluation of joint effects suggested that subjects with genotypes carrying variant alleles for both SNPs could be at particularly low risk (OR $(95 \% \mathrm{CI})$ for subjects with the rs6259 AG/GG and rs1799941 AG/GG genotypes ( 9 cases and 36 controls) was $0.47(0.22-1.02), p=0.06$, compared to common homozygous for both SNPs (122 cases and 237 controls). However, the interaction between these two SNPs was not statistically significant ( $p$ $=0.15$ ). None of the other SNPs evaluated were significantly associated with ovarian cancer risk. Associations with the SNPs evaluated in this report were not significantly modified by age, menopausal status, first degree family history of breast or ovarian cancer, or number of lifetime ovulatory cycles (data not shown). Associations were also not significantly modified by histological type or stage at diagnosis (data not shown).

Haplotype analyses including all non-redundant SNPs (i.e excluding rs1641536 and rs1641535 in ATP1B1) showed nine haplotypes with frequencies $>0.01$, with no significant overall association with ovarian cancer risk (global p = 0.42; Table 3). Only one haplotype, present in $5 \%$ of cases and controls, carried the D356N (rs6259) SNP and showed no significant association with risk compared to the haplotype carrying the common alleles for each of the SNPs evaluated (ATACCCCG). Although none of the individual haplotypes were significantly associated with risk, there was a borderline significant association for the most common haplotype (frequent in $35 \%$ of controls) which carried a variant for a SNP in the 5'UTR of SHBG (rs1799941). Data were consistent with an inverse association for women carrying this haplotype (GTACCCCG) compared to the ATACCCCG haplotype (OR $95 \% \mathrm{CI}=0.77(0.58-1.01)$; Table 3$)$.

\section{Discussion}

This detailed evaluation of common genetic variation in $S H B G$ including its neighboring gene ATP1B2, does not support a substantial association between common variants and ovarian cancer risk. However, the possibility of weak to modest associations could not be excluded.

The asparagine $(\mathrm{N})$ allele of $S H B G \mathrm{D} 356 \mathrm{~N}$ and the variant allele of the -67G>A 5'UTR SNP in SHBG have been asso- 
Table I: Personal and tumor characteristics of 264 ovarian cancer cases and 625 controls in the Polish Ovarian Cancer Study.

\begin{tabular}{|c|c|c|c|c|c|}
\hline & Cases $* N=264$ & & Controls* $N=625$ & & $\mathrm{P} * *$ \\
\hline \multicolumn{6}{|l|}{ Study site, N \% } \\
\hline Warsaw & 177 & $67 \%$ & 423 & $68 \%$ & 0.85 \\
\hline Lodz & 87 & $33 \%$ & 202 & $32 \%$ & \\
\hline Age, mean SD in years & 56.3 & 10.8 & 56.1 & 10.8 & 0.83 \\
\hline \multicolumn{6}{|c|}{ No. of full-term births, $\mathrm{N} \%$} \\
\hline Nulliparous & 50 & $19 \%$ & 79 & $13 \%$ & $<0.0001$ \\
\hline I & 101 & $38 \%$ & 176 & $28 \%$ & \\
\hline 2 & 94 & $36 \%$ & 273 & $44 \%$ & \\
\hline$\geq 3$ & 19 & $7 \%$ & 97 & $16 \%$ & \\
\hline $\begin{array}{l}\text { Number of ovulatory } \\
\text { cycles, mean SD }\end{array}$ & 410.9 & 71.1 & 398.1 & 81.3 & 0.03 \\
\hline \multicolumn{6}{|c|}{ Use of oral contraceptive, $\mathrm{N} \%$} \\
\hline Never & 245 & $94 \%$ & 556 & $90 \%$ & 0.08 \\
\hline Ever & 16 & $6 \%$ & 60 & $10 \%$ & \\
\hline \multicolumn{6}{|c|}{ Currently having menstrual periods, $\mathrm{N} \%$} \\
\hline No & 182 & $71 \%$ & 401 & $66 \%$ & 0.40 \\
\hline Yes & 75 & $29 \%$ & 203 & $34 \%$ & \\
\hline Unclear & 7 & $3 \%$ & 20 & $3 \%$ & \\
\hline \multicolumn{6}{|c|}{ Use of oral hormone replacement therapy among post-menopausal women } \\
\hline Never & 146 & $81 \%$ & 325 & $82 \%$ & \\
\hline Ever & 35 & $19 \%$ & 70 & $18 \%$ & 0.15 \\
\hline \multicolumn{6}{|c|}{ Family history of breast or ovarian cancer in first-degree relatives, $N \%$} \\
\hline No & 210 & $80 \%$ & 553 & $88 \%$ & 0.001 \\
\hline Breast cancer only & 26 & $10 \%$ & 24 & $4 \%$ & \\
\hline $\begin{array}{l}\text { Ovarian cancer } \\
\text { only }\end{array}$ & 26 & $10 \%$ & 40 & $6 \%$ & \\
\hline Both & 2 & $1 \%$ & 8 & $1 \%$ & \\
\hline \multicolumn{6}{|c|}{ Tumor Characteristics } \\
\hline \multicolumn{6}{|c|}{ Histology, N (\%) } \\
\hline Serous & 118 & $45 \%$ & & & \\
\hline Mucinous & 26 & $10 \%$ & & & \\
\hline Endometrioid & 58 & $22 \%$ & & & \\
\hline Clear cell & 14 & $5 \%$ & & & \\
\hline Mixed & 18 & $7 \%$ & & & \\
\hline $\begin{array}{l}\text { Others or } \\
\text { unclassified }\end{array}$ & 30 & $11 \%$ & & & \\
\hline Stage, $\mathrm{N} \%$ distant & 110 & $62 \%$ & & & \\
\hline $\begin{array}{l}\text { Not staged or } \\
\text { missing }\end{array}$ & 86 & & & & \\
\hline \multicolumn{6}{|c|}{ Grade of differentiation, N\% } \\
\hline Well & 21 & $13 \%$ & & & \\
\hline Moderate & 59 & $35 \%$ & & & \\
\hline Poor & 88 & $52 \%$ & & & \\
\hline Missing & 96 & & & & \\
\hline
\end{tabular}

* Differences between the total number of cases and controls and frequencies shown in the table are due to missing data.

** $\mathrm{P}$ values for categorical variables are based on chi squared tests, and on $\mathrm{t}$-tests for continuous variables. 
Table 2: Risk of epithelial ovarian cancer and polymorphisms in SHBG and its 3' neighbor ATPIB2, among 264 ovarian cancer cases and 625 controls in the Polish Ovarian Cancer Study*

\begin{tabular}{|c|c|c|c|c|c|c|}
\hline Gene SNP & & Cases & Controls & OR** & $95 \% \mathrm{Cl}$ & P-trend \\
\hline \multicolumn{7}{|l|}{ SHBG } \\
\hline rs|79994| & $\mathrm{AA}$ & 144 & 278 & 1.00 & & \\
\hline$-67 G>A$ & AG & 118 & 287 & 0.79 & $0.59-1.07$ & \\
\hline 5'UTR & GG & 23 & 57 & 0.79 & $0.46-1.33$ & 0.14 \\
\hline rs 6257 & TT & 242 & 520 & 1.00 & & \\
\hline \multirow[t]{2}{*}{ IVSI-I7T>C } & TC & $4 I$ & 91 & 0.97 & $0.65-1.44$ & \\
\hline & $\mathrm{CC}$ & 2 & 2 & 2.13 & $0.29-15.3$ & 0.75 \\
\hline rs6259 & AA & 254 & 547 & 1.00 & & \\
\hline$E \times 8+6 G>A$ & $A G$ & 30 & 72 & 0.89 & $0.57-1.40$ & \\
\hline D356N & GG & 1 & 4 & 0.51 & $0.06-4.65$ & 0.72 \\
\hline rs727428 & $\mathrm{CC}$ & 119 & 264 & 1.00 & & \\
\hline \multirow{2}{*}{$\begin{array}{l}I|2| \text { bp } 3^{\prime} \text { of STP } \\
T>C\end{array}$} & CT & 121 & 278 & 0.96 & $0.71-1.30$ & \\
\hline & TT & 45 & 81 & 1.25 & $0.81-1.91$ & 0.48 \\
\hline rsI64I544 & $\mathrm{CC}$ & 261 & 580 & 1.00 & & \\
\hline \multirow{2}{*}{$\begin{array}{l}31959 \text { bp } 3^{\prime} \text { of STP } \\
T>C\end{array}$} & $\mathrm{CT}$ & 22 & 38 & 1.34 & $0.77-2.33$ & 0.30 \\
\hline & $\mathrm{TT}$ & I & 0 & & & \\
\hline \multicolumn{7}{|l|}{ ATPIB2 } \\
\hline rsl64I537 *** & $\mathrm{CC}$ & 215 & 486 & 1.00 & & \\
\hline \multirow[t]{2}{*}{$-9115 T>C$} & $\mathrm{CT}$ & 66 & 125 & 1.21 & $0.86-1.71$ & \\
\hline & TT & 3 & 8 & 0.90 & $0.23-3.46$ & 0.36 \\
\hline rsl624085 & $\mathrm{CC}$ & 116 & 246 & 1.00 & & \\
\hline \multirow{2}{*}{$E \times 2 G>C$} & CG & 120 & 292 & 0.86 & $0.64-1.18$ & \\
\hline & GG & 49 & 84 & 1.25 & $0.82-1.90$ & 0.60 \\
\hline rs 1641512 & GG & 193 & 401 & 1.00 & & \\
\hline \multirow[t]{2}{*}{$E \times 7+4 \mid 4 G>A$} & GA & 80 & 195 & 0.86 & $0.63-1.17$ & \\
\hline & $\mathrm{AA}$ & 12 & 27 & 0.94 & $0.46-1.90$ & 0.42 \\
\hline
\end{tabular}

* Differences between the total number of cases and controls and frequencies shown in the table are due to missing genotype data.

** Adjusted for age and city.

*** Highly correlated with ATPIBI rs I64I536 (I8852T>C) and rs I64I535 (-8703T>c), $\mathrm{r}^{2}>0.98$, not shown in table to avoid redundancy.

ciated with elevated SHBG circulating levels [5-7]. Therefore, these SNP could result in a reduced bioavailability of estrogen or other sex-steroids, and a reduction in risk of hormonally-related cancers. Although the frequency of the genotypes with the variant alleles for these two SNPs was lower for cases than controls, differences were not statistically significant. A pentanucleotide (TAAAA) $n$ repeat polymorphism, not measured in our study, has been found to be linked to the D356N SNP in Caucasian populations, as well as associated with elevated levels of SHBG [7]. Therefore, it is possible that functional changes not directly measured in our study might be related to risk. Given the lack of data from previous studies of ovar- ian cancer on the common variation in $S H B G$, further studies are needed to clarify potential relationships.

The main limitation of this study was limited power to detect weak to modest associations. Specifically, the study size provided $80 \%$ power to detect ORs of 1.5 or 0.7 for MAFs ranging from 0.10 to 0.50 , assuming an additive mode of inheritance; and MAFs ranging from 0.20 to 0.35 , assuming a dominant inheritance. However, the power to detect associations for MAF outside these ranges, recessive associations, or gene-gene/gene-environment interactions was low. Therefore, such associations could have missed in our study. 
Table 3: Risk of epithelial ovarian cancer and SHBG-ATPIB2 extended haploptypes, among 264 ovarian cancer cases and 625 controls in the Polish Ovarian Cancer Study

\begin{tabular}{|c|c|c|c|c|c|c|c|c|c|c|c|c|}
\hline \multirow[b]{3}{*}{ A } & \multirow[b]{3}{*}{$\mathrm{T}$} & \multirow[b]{3}{*}{$A$} & \multirow{2}{*}{\multicolumn{2}{|c|}{ Haplotypes* }} & & & & \multicolumn{2}{|c|}{ Haplotype frequency } & \multirow[t]{2}{*}{ OR } & \multirow[t]{2}{*}{$95 \% \mathrm{Cl}$} & \multirow[t]{2}{*}{$P$} \\
\hline & & & & & & & & Cases & Controls & & & \\
\hline & & & C & C & C & $\mathrm{C}$ & G & 0.26 & 0.20 & 1.00 & (reference $\left.{ }^{* *}\right)$ & \\
\hline G & . & . & . & . & . & . & . & 0.32 & 0.35 & 0.77 & $0.58-1.01$ & 0.06 \\
\hline . & . & . & . & . & . & G & $A$ & 0.01 & 0.02 & 0.43 & $0.14-1.33$ & 0.14 \\
\hline . & . & . & $\mathrm{T}$ & . & . & G & . & 0.12 & 0.11 & 0.89 & $0.60-1.33$ & 0.58 \\
\hline . & . & . & $\mathrm{T}$ & . & $\mathrm{T}$ & G & $A$ & 0.09 & 0.09 & 0.83 & $0.56-1.23$ & 0.36 \\
\hline . & . & . & $\mathrm{T}$ & $\dot{\mathrm{T}}$ & $\mathrm{T}$ & G & A & 0.04 & 0.03 & 1.22 & $0.70-2.12$ & 0.49 \\
\hline . & . & G & $\mathrm{T}$ & . & . & G & $A$ & 0.05 & 0.05 & 0.81 & $0.50-1.30$ & 0.38 \\
\hline . & C & . & $\mathrm{T}$ & . & . & G & . & 0.07 & 0.07 & 0.81 & $0.53-1.25$ & 0.34 \\
\hline G & . & . & . & . & . & G & . & 0.01 & 0.02 & 0.51 & $0.17-1.58$ & 0.24 \\
\hline
\end{tabular}

* Polymorphic bases in 5' to 3' order: SHBG (rs 179994I, rs6257, rs6259, rs727428, rs I64I544); ATPIB2 (rs I644I537, rs I624085, rs I64I5I2). Two ATPIB2 SNPs ( $r$ I 1641536 and rs 1641535$)$ highly correlated $\left(r^{2}>0.98\right)$ with $r s 1641537$ are not included in the analyses.

*** The reference

This population-based study has among the highest participation rate attained in population-based studies with collection of biological specimens. However, collection of DNA samples inevitably reduces overall participation rates and could introduce selection bias. This bias is unlikely to be of relevance in this report because the evaluated SNPs are unlikely to be related to potential selection factors. Further, the observed allele frequency for the SHBG D356N was similar to previously published studies among Caucasians [6], and the distribution of ovarian cancer risk factors in cases and controls was consistent with known or suspected risk factors for ovarian cancer [15].

\section{Conclusion}

This report of a detailed assessment of genetic variation in $S H B G$ including its neighboring gene ATP1B2, does not support a substantial association between common variation in this region and ovarian cancer risk. However, weak or modest associations could not be excluded, particularly a reduced risk of ovarian cancer hypothesized for the functional SNPs D356N and -67G>A 5'UTR. Therefore, further evaluation in larger study populations is warranted.

\section{Abbreviations}

ATP1B2 - ATPase, $\mathrm{Na}+\mathrm{K}+$ transporting beta 2 polypeptide

CI - confidence interval

LD - linkage disequilibrium

LRT - likelihood ratio test

MAF - minor allele frequency
OR - odds ratio

SHBG - sex hormone-binding globulin

SNP - single nucleotide polymorphisms

TP53 - tumor protein p53 (Li-Fraumeni syndrome)

\section{Competing interests}

The author(s) declare that they have no competing interests.

\section{Authors' contributions}

MG-C participated in the design of the study and data collection, performed the statistical analysis and wrote the paper; MY, LB, RW and SJC participated in the selection and performance of genotyping assays; LAB, JL, NS-D, BP, A B-M, WZ participated in the design of the study and data collection; MES participated in the design of the study and carried out the pathology review; YQ and DR helped with the statistical analyses. All authors were involved in the drafting of the manuscript, read and approved the final manuscript.

\section{Additional material}

\section{Additional File 1}

Supplementary Figure 1: Patterns of linkage disequilibrium across the SHBG and its 3' neighbor gene ATP1B2. The figure provided shows Patterns of linkage disequilibrium across the SHBG and its 3 ' neighbor gene ATP1B2.

Click here for file

[http://www.biomedcentral.com/content/supplementary/14712407-7-60-S1.doc] 


\section{Acknowledgements}

This research was supported by the Intramural Research Program of the $\mathrm{NIH}$, National Cancer Institute, Division of Cancer Epidemiology and Genetics and the Center for Cancer Research. We thank Anita Soni (Westat, Rockville, MD) for her work on study management for the Polish ovarian cancer study; Pei Chao (IMS, Silver Spring, MD) for her work on data and sample management; and physicians, nurses, interviewers and study participants for their efforts during filed-work.

\section{References}

I. Risch HA: Hormonal etiology of epithelial ovarian cancer, with a hypothesis concerning the role of androgens and progesterone. J Natl Cancer Inst 1998, 90: 1774-1786.

2. Lukanova A, Lundin E, Akhmedkhanov A, Micheli A, Rinaldi S, Zeleniuch-Jacquotte A, Lenner P, Muti P, Biessy C, Krogh V, Berrino F, Hallmans G, Riboli E, Kaaks R, Toniolo P: Circulating levels of sex steroid hormones and risk of ovarian cancer. Int J Cancer 2003, 104:636-642.

3. Helzlsouer KJ, Alberg AJ, Gordon GB, Longcope C, Bush TL, Hoffman SC, Comstock GW: Serum gonadotropins and steroid hormones and the development of ovarian cancer. JAMA 1995, 274:1926-1930.

4. Selby C: Sex hormone binding globulin: origin, function and clinical significance. Ann Clin Biochem 1990, 27 ( Pt 6):532-54|.

5. Cousin P, Calemard-Michel L, Lejeune H, Raverot G, Yessaad N, Emptoz-Bonneton A, Morel Y, Pugeat M: Influence of SHBG gene pentanucleotide TAAAA repeat and $\mathrm{D} 327 \mathrm{~N}$ polymorphism on serum sex hormone-binding globulin concentration in hirsute women. J Clin Endocrinol Metab 2004, 89:917-924.

6. Dunning AM, Dowsett M, Healey CS, Tee L, Luben RN, Folkerd E, Novik KL, Kelemen L, Ogata S, Pharoah PD, Easton DF, Day NE, Ponder BA: Polymorphisms associated with circulating sex hormone levels in postmenopausal women. J Natl Cancer Inst 2004, 96:936-945.

7. Haiman CA, Riley SE, Freedman ML, Setiawan VW, Conti DV, Le Marchand L: Common genetic variation in the sex steroid hormone-binding globulin (SHBG) gene and circulating shbg levels among postmenopausal women: the Multiethnic Cohort. J Clin Endocrinol Metab 2005, 90:2198-2204.

8. A L, L B, YM LV, S P, Gerhadt D, Tarazona-Santos, D GR, PE L, VN K, S C: Pattern of genetic variation in the TP53 locus indicates linkage disequilibrium extends across the flanking genes, ATPIB2 and WDR79. 2007.

9. BR P, Yeager M, L B, R W, M B, L Q, Sicotte $H, B S, M A, A C, A E, V$ P, DS G, SJ C: SNP500Cancer: A Public Resource for Sequence Validation, Assay Development, and Frequency Analysis for Genetic Variation in Candidate Genes. Nuc Acids Res 2006, 34 (Database Issue):D617-D62I.

10. 2007 [http://snp500cancer.nci.nih.gov].

II. Webb PM, Green A, Cummings MC, Purdie DM, Walsh MD, Chenevix-Trench G: Relationship between number of ovulatory cycles and accumulation of mutant p53 in epithelial ovarian cancer. J Natl Cancer Inst 1998, 90:1729-I734.

12. 2007 [http://www.broad.mit.edu/mpg/haploview/index.php].

13. Schaid D]: Evaluating associations of haplotypes with traits. Genet Epidemiol 2004, 27:348-364.

14. 2007 [http://mayoresearch.mayo.edu/mayo/research/biostat/ schaid.cfm].

15. NS W, LS C, DC F, KA R: Ovarian Cancer. In Cancer Epidemiology and Prevention Edited by: D S and JF F. New York, Oxford University Press; 1996:1040-1057.

\section{Pre-publication history}

The pre-publication history for this paper can be accessed here:

http://www.biomedcentral.com/1471-2407/7/60/prepub http://www.biomedcentral.com/1471-2407/7/60 